\title{
Influence of Hedging Cost upon Weather Derivatives Pricing
}

\author{
Teng Lei \\ Business School, Chengdu University of Information Technology, Chengdu, China
}

Email address:

tenglei@cuit.edu.cn

\section{To cite this article:}

Teng Lei. Influence of Hedging Cost upon Weather Derivatives Pricing. Journal of Finance and Accounting. Vol. 4, No. 4, 2016, pp. $234-238$. doi: $10.11648 /$ j.jfa.20160404.19

Received: January 24, 2016; Accepted: February 29, 2016; Published: June 30, 2016

\begin{abstract}
Weather derivatives play a major role in risk management of non-catastrophic weather market. The healthy development of the derivatives market is inseparable from the reasonable pricing of the product itself. As non-traditional financial derivatives, weather derivatives can provide a good risk hedging. Meanwhile, in the weather derivatives market, brokers play an even more important part than in the traditional financial derivatives market. Therefore, when pricing weather derivatives, we must take two factors into consideration, namely, brokers as market makers as well as the impact of their hedging cost on weather derivatives pricing. Based on the expected claims and risk payment of basic derivatives contracts, this paper is going to discuss weather derivatives pricing on the basis of hedging costs, while taking into account the impact of market makers' hedging costs, risk aversion and existing positions.
\end{abstract}

Keywords: Weather Derivatives, Hedging, Market Makers

\section{Introduction}

Weather derivatives constitute the core products in weather risk market. Represented by CDD, HDD and EDD (Energy temperature value), particularly, weather derivatives continue to play a significant role in non-catastrophic weather markets risk management. Weather derivatives market currently concentrated in North America, Western Europe and Japan and other developed economies, and it has implemented the transfer of general weather risk to third parties willing to and capable of dealing such risk successfully, met the demands of transfer and avoid the risk in energy, agriculture, tourism, transportation and other weather-sensitive industries.

In China, the development of weather derivatives market requires enhanced awareness of participation and dodging risk of all relevant aspect, requires further development and expansion of traditional financial markets, requires further market-oriented reform of the meteorological system. And most importantly, the core lies in weather derivatives pricing. Although the weather risk contracts cannot replace the traditional traded assets, such as securities or bonds, thus we cannot evaluate targeted contracts using different contracts for the same kind of risk, the presence and growth of weather derivatives market still provide relevant market information and skills for hedging. Accordingly, the pricing method of weather risk can also draw lessons from that of insurance and traditional derivatives, such as actuarial pricing and market pricing. These pricing methods can price weather derivatives contracts well, but they are exercised in an isolated way for they merely focus on single contracts. As for the weather derivatives market, brokers who serve as market makers play a particularly important role. This is because the weather derivatives market, despite faced with strong demand, still lacks liquidity significantly, plus small trading volume as a result of respectively-long-time trading execution, which result in insufficient profit to support the brokerage industry operation. Therefore, in the study of pricing of weather derivatives, it is necessary to consider the role of market makers, such as the effect of market makers' hedging motivation and existing risk positions on pricing.

In the weather derivatives markets, both the existed observing prices and market makers' risk positions are essential in the process of forming the final trading prices of weather derivatives. Market observing price of weather contract affects product pricing process in two ways. On the one hand, the price based on normal distribution of historical weather data may not fully reflect its actual value; the market price is likely 
to reflect the information which the historical weather data do not include. Such information may include forecast information, supply and demand forces, observatories change data or other primitive historical data that preliminary traders wrongly interpreted. Market makers are likely to be interest in how others price the similar risk. Such interest may make it possible for market makers to recognize the situation that pricing model does not reflected and other factors should be considered. Market prices may prompt the cost when hedging the weather transaction positions. For example, there has been an agreement of former transaction, and the former price can represent the current trading prices in some way, then such transaction is very important. On the other hand, for market makers, despite the unlikely implementation of fully hedging, the use of the relevant contracts to hedge some of the risk is achievable. In this case, hedging may be static; it also may need reassess as time goes by and the market condition changes. Whether in any case, the cost of establishing hedging positions surely will affect the market makers' bid or ask price to get the desired returns and the market pricing for weather derivatives.

\section{Influence of Hedging Cost}

\subsection{The Relative Value and Hedging Costs}

For such weather index products as HDD or CCD, we assume that they are normally distributed, then we can use the mean and standard deviation to describe its statistical characteristics. Of course, for HDD and CDD indices, we need to further process by way of trend determination so as to use them in the approach mentioned above to obtain all the information to calculate the expected payment claims and risk payment statistics. Whatever circumstances it may be, as long as the mean and standard deviation values are available, we can measure the statistics of expected claims and the risk payment. Conversely, if the market price of options or swaps can be observable, we can export the market value meaning of index mean and standard deviation. For instance, we can calculate the expected payment for a swap whose exercise price is $\mathrm{K}$, loss ratio is $\mathrm{N}_{0}$, payment ceiling is $\mathrm{L}$, when the index conform the normal distribution $\mathrm{N}(\mu, \sigma)$. If we assume that a reasonable exercise price is the price that makes expected claims zero, then the inevitable exercise price must be $\mu$, that is the average of the underlying asset distribution. In this way, we can deduce the mean of market implications from the market level K of swap:

$$
\mu_{\mathrm{m}}=\mathrm{k}
$$

If we want to use existed swaps to hedge against an option position, we need to calculate the value changed in a contract on options and swaps while the expected value of basic assets increases by one unit. This number can be represented by $\Delta$ :

$$
\begin{aligned}
& \Delta\left(\mu, \sigma ; \varphi, \mathrm{N}_{0}, \mathrm{~K}, \mathrm{t}, \mathrm{T}, \mathrm{L}\right)=\frac{\partial \mathrm{E}\left(\mu, \sigma ; \varphi, \mathrm{N}_{0}, \mathrm{~K}, \mathrm{t}, \mathrm{T}, \mathrm{L}\right)}{\partial \mu} \\
& =\Delta\left(\mu, \sigma ; \varphi, \mathrm{N}_{0}, \mathrm{~K}, \mathrm{t}, \mathrm{T}\right)-\Delta\left(\mu, \sigma ; \varphi, \mathrm{N}_{0}, \mathrm{~K}+\varphi \frac{\mathrm{L}}{\mathrm{N}_{0}}, \mathrm{t}, \mathrm{T}\right)
\end{aligned}
$$

$\mathrm{E}\left(\mu, \sigma ; \varphi, \mathrm{N}_{0}, \mathrm{~K}, \mathrm{t}, \mathrm{T}, \mathrm{L}\right)$ is the mathematical expectation of a contract with payment ceiling $\mathrm{L}$, whose pricing time is $t$, the expiration time is $T$. Such a contract can be viewed as the superposition of a non-payment ceiling long and short contracts, thus:

$$
\mathrm{E}\left(\mu, \sigma ; \varphi, \mathrm{N}_{0}, \mathrm{~K}, \mathrm{t}, \mathrm{T}, \mathrm{L}\right)=\mathrm{E}\left(\mu, \sigma ; \varphi, \mathrm{N}_{0}, \mathrm{~K}, \mathrm{t}, \mathrm{T}\right)-\mathrm{E}\left(\mu, \sigma ; \varphi, \mathrm{N}_{0}, \mathrm{~K}+\varphi \frac{\mathrm{L}}{\mathrm{N}_{0}}, \mathrm{t}, \mathrm{T}\right)
$$

And the mathematical expectation of non-payment ceiling contracts is:

$$
\mathrm{E}\left(\mu, \sigma ; \varphi, \mathrm{N}_{0}, \mathrm{~K}, \mathrm{t}, \mathrm{T}\right)=\mathrm{N}_{0}\left[\frac{\sigma}{\sqrt{2 \pi}} \mathrm{e}^{\frac{-(\mathrm{K}-\mu)^{2}}{2 \sigma^{2}}}+\varphi(\mathrm{K}-\mu) \mathrm{N}(\varphi(\mathrm{K}-\mu) / \sigma)\right]
$$

Here, $\varphi$ is the index used to distinguish the nature of contracts. For a call option the value is 1 , and the put option -1 ; $\mathrm{N}(\bullet)$ is the Cumulative distribution function of standard normal distribution $\mathrm{N}(0,1)$.

For an option without payment ceiling, changes in contract value caused by the expected value changes of per unit underlying asset are:

$$
\Delta\left(\mu, \sigma ; \varphi, \mathrm{N}_{0}, \mathrm{~K}, \mathrm{t}, \mathrm{T}\right)=\varphi \mathrm{N}_{0} \mathrm{D}(\mathrm{t}, \mathrm{T}) \mathrm{N}(\varphi(\mathrm{K}-\mu) / \sigma)
$$

Since we know that swap can be considered as hedging options consist of long calls options and short put options, therefore, the formula (1) and (4) can calculate the changes in contract value caused by the expected value changes of per unit underlying asset in a swap contract.

For contracts based on those listed assets of circulation, say, contracts in the various types of securities and derivatives markets, option delta value represents the necessary hold number of stock in order to hedge against the option short-term changes caused by stock price changes. For all dynamic hedging strategies, delta value is a key issue. But for the weather contracts, the dynamic hedging performed in this way may not be achieved, but it can help us to find a reasonable static hedging direction. As we all know, for normally distributed index, delta value is the number that must be hedged to minimize the variance of option with added swap-position. If we use swaps to hedge option position, then we are going to calculate the value $\mu_{\mathrm{m}}$ when pricing option. That is to adjust option theoretical value which equals to any 
additional costs or benefits related to hedging strategies.

\subsection{An Example of Adjustment of Contract Asking Price on Impact of Hedging Cost}

To understand the above pricing process better, we can assume there are some contract price information in the market, such as the existence of a swap contract whose price ranging from 3500 to 3550 in the winter. Now assuming a swap contract is clinched at the price of 3510 , we can trade with the same price when hedge against long or short contracts.
At the same time we assume that the historical HDD or CDD data are subject to the normal distribution $\mu_{\mathrm{m}}=3600$, $\sigma_{\mathrm{m}}=210$, then for a put option, whose exercise price is 3510 , loss ratio is 5000, payment ceiling is one million, we can calculate from its cumulative distribution function of standard normal distribution that $\mathrm{N}(\varphi(\mathrm{K}-\mu) / \sigma)=\mathrm{N}(90 / 210)=0.6659$; According to equation (2) and (3, we can see the expected payments of options are:

$$
\begin{aligned}
& \mathrm{E}\left(\mu, \sigma ; \varphi, \mathrm{N}_{0}, \mathrm{~K}, \mathrm{t}, \mathrm{T}, \mathrm{L}\right)=\mathrm{E}\left(\mu, \sigma ; \varphi, \mathrm{N}_{0}, \mathrm{~K}, \mathrm{t}, \mathrm{T}\right)-\mathrm{E}\left(\mu, \sigma ; \varphi, \mathrm{N}_{0}, \mathrm{~K}+\varphi \frac{\mathrm{L}}{\mathrm{N}_{0}}, \mathrm{t}, \mathrm{T}\right) \\
& =5000 \times\left[\frac{210}{\sqrt{2 \pi}} \mathrm{e}^{\frac{-(3510-3600)^{2}}{2 \times 210^{2}}}-(3510-3600) \times 0.6659\right] \\
& -5000 \times\left[\frac{210}{\sqrt{2 \pi}} \mathrm{e}^{\frac{-(3310-3600)^{2}}{2 \times 210^{2}}}-(3310-3600) \times \mathrm{N}\left(\frac{3600-3310}{210}\right)\right] \\
& =971659
\end{aligned}
$$

If we sell out the put option in a contract, then we are actually going long to this contract. In this way we can try to sell the contract swaps to partly hedge against the risk of options positions According to equation (1) and (4), we can calculate the delta value is -1253 of a short option position whose loss ratio is 5000 , payment cap is 1000000 , while the short swap positions delta value is 1829 . So the best swap hedging for an option position is to take short swap valued $3425(1253 \times 5000 \div 1829)$. However, when we estimate the average is 3600 and sell out the swap contract at 3510, our expected loss is $-112770(-1253 \times(3600-3510))$, or that additional revenue is 112,770 . Under the premise of risk-free arbitrage, or taking into account hedging costs, we can only make adjustments to our asking price with this extra (hedging costs), which will make the actual option price change from 971659 to 858889 (971659-112770)

This is only considering the impact of swap level on option pricing. Of course, the market price of an option contract will also give us some useful information to use option contracts themselves to hedge against the risk of their own.

\section{Influence of Existing Positions}

\subsection{Risk Cost of Existing Positions and Portfolio}

We assume that the risk payments of such contracts positions as weather options or swaps depend on the historical statistics of contract payments and the existing portfolio or positions of market makers. And we denote risk payment statistics as $\mathrm{R}(\mathrm{P}, \mathrm{CP})$, where $\mathrm{P}$ is the final price of the contract or payment amount, $\mathrm{CP}$ represents existing positions. Unlike simple positions on the contract, the existing contract positions are indicators of market makers' risk sensitivity to the contract index value. This sensitivity may be direct, say, when market makers have built their positions on contracts with the same index. But if market makers build their financial products contracts based on any other related or unrelated index contract this sensitivity is considered to be indirect. This sensitivity expressed by existing positions may be found in various types of financial products, including the weather derivatives.

when market makers' existing positions are zero, a certain weather options whose expected claim is $\mu$ and standard deviation is $\sigma$, can be priced it as follows:

$$
\mathrm{P}=\mathrm{D}(\mathrm{t}, \mathrm{T})(\mu \pm \alpha \sigma)
$$

Where $\mathrm{D}(\mathrm{t}, \mathrm{T})$ is the discount factor between the expiration time $\mathrm{T}$ and contract pricing time $\mathrm{t}, \alpha$ is the risk aversion denoted in the form of Sharpe ratio.

So when the position is not zero, the above equation can be generalized to

$$
\mathrm{P}=\mathrm{D}(\mathrm{t}, \mathrm{T})(\mu \pm \alpha(\sigma(\mathrm{P}, \mathrm{CP})-\sigma(\mathrm{CP})))
$$

Here, the standard deviation $\sigma$ is a function of the contract payment $P$ and existing positions CP; price of weather option calculated by using this formula makes market makers to maintain their entire portfolio risk costs sure. In addition, the covariance of this equation:

$$
\sigma(\mathrm{P}, \mathrm{CP})=\sqrt{\sigma^{2}(\mathrm{P})+\sigma^{2}(\mathrm{CP})+2 \rho(\mathrm{P}, \mathrm{CP}) \sigma(\mathrm{P}) \sigma(\mathrm{CP})}
$$

Among them, $\sigma(\mathrm{P})$ and $\sigma(\mathrm{CP})$ are the standard deviation of contractual claims and existing positions, $\rho(P, C P)$ is the correlation coefficient of claims and the existing position. Because $-1<\rho<1, \sigma(\mathrm{P}, \mathrm{CP})$ can be either bigger or smaller than the original one. Proportion coefficient of $\alpha$ in the formula (5) represents the increment of portfolio risk. When this coefficient is positive, such transactions under the current position will increase the risk of market makers, and when this coefficient is negative, similar transactions under the current 
position can reduce the risk. Weather the risk is increased or reduced depends on the correlation coefficient between the contract and the current positions, and the relative number of $\sigma(\mathrm{P})$ and $\sigma(\mathrm{CP})$. During the actuarial pricing, despite the fact that the counterparty may use the same way to calculate the risk, have the same appetite for risk, and all choose not to hedge existing positions, but each party in the transactions may have their risk positions improved due to the contrary trading; so they may not agree on a fair price contract terms then the transaction can occur.

\subsection{An Example of Influence of Existing Positions on Weather Swaps Pricing}

The weather swaps is a contract that requires payments were paid by participants when weather index rises above a certain level (or drops below a certain level), and guarantees the participants are paid weather index fell below the same level (or rises above the same level)

Thus, according to a change in the weather indicator values, participants may either be payer or benefiters. In this sense, swapping equals to exercise the hedging options with the same price. Swap contracts do not appear in trading contracts of the end customer often based on the following reasons: First, to clinch the trade, end customers need to find their counterparty at their expected price levels (the higher, the better) which is interchangeable. Second, the end customer is likely to retain the possibility that income is more than the expected, so they are more inclined to choose various types of options products. Thirdly, although the relevance between weather and such indicators as sales in some industries is relatively high, they are rarely perfectly correlated. And the imperfectly correlated lead to that the swaps cannot bring the desired result of lower protection. Therefore, swaps products are often dealing between the end customer and weather derivatives broker transactions. And it is particularly important to understand the impact of hedging cost on price while brokers play the market makers roles.

Take a down garment manufacturer, the cold of winter can drive sales of its jacket, which brought excess earnings, and warm winter will damage its sales revenue, so the HDD for the jacket producers is long. So the manufacturer can set the exercise price at $3000 \mathrm{HDD}$ by reaching an exchange agreement with weather derivatives brokers, then the company can eliminate uncertainty income brought by weather change so that the sales revenue received is at the expected level, no more, no less. The influence of swap agreement on its sales revenue is represented by the following diagram:

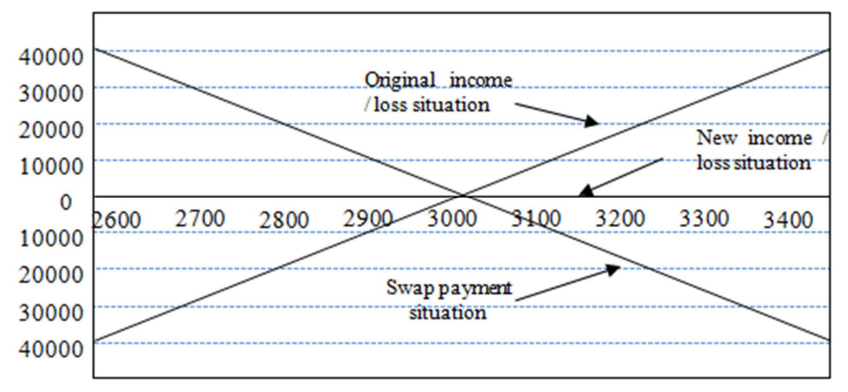

Figure 1. Influence of Swap Agreement on its Sales Revenue.
Suppose the down manufacturer analyses that effective contract payment is long HDD 20000 yuan per kWh, the local winter (assuming each year from November to next March) standard deviation of the HDD index is 350 according to historical statistics, then the standard deviation of sales revenue changes caused by weather changes is 7 million yuan $(350 \times 20000)$. The down manufacturer decides to conduct hedging of payment at 20,000 yuan per degree under the condition that payment caps is large enough and is away from the exercise price, as well as discount factor $\mathrm{D}(\mathrm{t}, \mathrm{T})$ is approximately equal to 1 . Local winter HDD index is subject to the normal distribution with the mean of 3000 , the standard deviation of 350 . Both the down jacket manufacturers and weather derivatives brokers are using standard deviation to quantify the risk, and using the equation $\alpha=10 \%$ to convert standard deviation to equivalent amount returns. Thus, the down jacket manufacturers can use the following equation (1) to calculate the breakeven asking price in order to determine their exercise price:

$$
\mathrm{P}=\mathrm{D}(\mathrm{t}, \mathrm{T})(\mu \pm \alpha \sigma)=3000-10 \% \times 350=2965
$$

Because the transaction can reduce the risk of end-users, so the end user can also sell contracts using the price below the expectations. Weather derivatives brokers apply the same formula to calculate its bid. But if the broker has a combination of weather contracts, so they tend to add any risk trading positions accumulated into its portfolio. In this case, we assume that standard deviation of its existing portfolio positions is 20 million, while assuming that the portfolio with the region in winter HDD index independent and there is no correlation, then, added risk costs of building long positions HDD index are:

$$
\alpha(\sigma(\mathrm{P}, \mathrm{CP})-\sigma(\mathrm{CP}))=10 \% \times\left(\sqrt{2000^{2}+700^{2}}-2000\right)=11.9
$$

So, the exercise price of the swap contract breakeven that the broker bids will be: 2994.05 HDDS (3000-11.9 $\div 2)$. As a result, for the broker, any price lower than the exercise price 2994.05 are profitable, while production of commercial jacket sold at any price above the 2994.05 HDD index will profit. Different risk positions of end users and brokers make them likely to agree with a certain exercise price benefiting both parties.

\section{Conclusion}

For the weather derivatives market, due to the role of market makers, pricing is bound to be constantly adjusted according to the actual hedging strategy and existing positions, that is to say, market information has a negligible impact on the final price formation. This requires a deep understanding of market information and appropriate use of proper tools. For example, the normal distribution assumption used in EDD contract pricing is the key to understand the pricing process. Using two indices parameters: $\mu$ and $\sigma$, normal model reflected the specific conditions of the contract in the price. This makes it possible for us to to derive the market meaning of these 
parameters by using market information. At the same time, these numerical values will in turn be used in pricing other contracts that have not traded yet. Although there is a big limitation to the weather derivatives market liquidity, compared to the traditional financial market, and thus the discussion of the meaning of these market values are sometimes limited to the theoretical level, it can also provide us with good ideas and directions when evaluating the relative value. In the case of those who can get the market price, it provides a method for pricing the contract when hedging costs involved.

Market Makers' existing positions and portfolios represent their sensitivity to the index value. This discussion helps to understand market makers' risk measurement methods, risk appetite and intention to hedge as well as their specific hedging strategies. The series of actions will lead to changes in the contract price, and ultimately makes the pricing of weather derivatives approach to the level of risk-free arbitrage.

\section{Acknowledgements}

Supported by Research Center of Meteorological Disaster Prediction/Pre-warning and Emergency Management (Security Management of Meteorological Disaster Risk in China, ZHYJ15-YB07).

\section{References}

[1] Liu Yuanyuan Rethinking weather derivative products and financial derivatives function [J] International Financial Research, 2005 (8): 53-56.

[2] Chen Jing weather futures development and application in China [J] Shanghai Financial, 2004 (12): 10-13.

[3] Guo Shuhua Lu Xiaolong development, application and prospects of weather derivatives product research [3], [J] Economist, 2008 (2): 68-69.

[4] Eric Banks weather risk management: markets, products and applications [M] // Li Guohua Beijing: Economic Management Press, 2011: 177-182.
[5] Liu Guoguang- weather forecasts and weather derivatives pricing research, [J] 2006 (6): 28-33.

[6] Liu Guoguang, Mao Ning stochastic model of the temperature and the temperature of option Pricing [J] Mathematical Statistics and Management, 2008 (6): 959-967.

[7] LEE, Min Xia, Liang Liming weather derivatives OU Pricing Model - A Case Study in temperatures forecast options, 2012 (2), 18-37.

[8] Xie Shiqing, Meiyun Yun weather derivatives operation mechanism and Actuarial Pricing: Theory and Practice of Finance and Economics. 2011 (6), 39-43.

[9] Chen Baishuo, Lishou Wei, He Jianmin, Cao Jie. Temperature Prediction Model of weather derivatives in varying mean reversion. Management Engineering. 2014 (2), 145-150.

[10] Debbie J, Dupuis. Forecasting temperature to price CME temperature derivatives. [J] International Journal of Forecasting, 27 (2011): 602-618.

[11] Zapranis A, Alexandridis A. Modeling the temperature time-dependent speed of mean reversion in the context of weather derivatives [J]. Applied Mathematical Finance, 2008, 15 (4): 355-386.

\section{Biography}

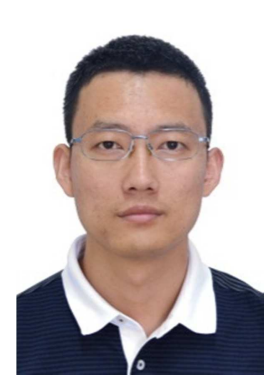

Teng Lei (1983), male, Shandong Dezhou, Master, lecturer of Business school in Chengdu University of Information Technology, research direction: financial markets 